Kumawula, Vol. 3, No.2, Agustus 2020, Hal 225 - 238 DOI: https://doi.org/10.24198/kumawula.v3i2.26909

ISSN 2620-844X (online)

Tersedia online di http://jurnal.unpad.ac.id/kumawula/index

\title{
PENGUATAN KAPASITAS PENGELOLAAN BUMDES CIPTA RAHAYU DI DESA CIPANJALU KECAMATAN CILENGKRANG KABUPATEN BANDUNG
}

\author{
Ida Widianingsih ${ }^{1}$, Haris Setiawan², Mifta Chuddin ${ }^{3}$ \\ ${ }^{1}$ Pusat Studi Desentralisasi dan Pembangunan Partisipatif, FISIP Universitas Padjadjaran, Indonesia \\ ${ }^{2}$ Sacita School of Social Business \\ ${ }^{3}$ Sacita Community and Product Development \\ 1*idawd@yahoo.com, ${ }^{2,3}$ hallo@sacitamuda.com
}

\begin{abstract}
ABSTRAK
Artikel ini menjelaskan kegiatan Pengabdian Kepada Masyarakat (PKM) dosen Unpad pada Semester Ganjil 2019/2020 yang dilaksanakan di Desa Cipanjalu, Kecamatan Cilengkrang, Kabupaten Bandung. Pemilihan lokasi PKM disesuaikan dengan penugasan penulis pertama sebagai Dosen Pembimbing Lapangan (DPL) untuk kegiatan Kuliah Kerja Nyata Mahasiswa (KKNM Kewirausahaan) Unpad yang dilaksanakan selama 1 bulan (9 Januari 2020-12 Februari 2020). Dalam kegiatan PKM ini, pengumpulan data dilakukan sejak penempatan mahasiswa KKN di Desa Cipanjalu melalui observasi, diskusi, wawancara dan FGD. Kegiatan evaluasi kinerja mandiri BUMDes Cipta Rahayu ditujukan untuk memperkuat kapasitas pengelolaan BUMDes Cipta Rahayu agar dapat mengoptimalkan fungsinya sebagai motor penggerak perekonomian masyarakat Desa Cipanjalu. Pelaksanaan evaluasi kinerja mandiri dilakukan secara informal yang dihadiri oleh dua orang pengurus inti, satu orang Pembina BUMDes, dan tiga orang fasilitator. Dari proses tersebut terungkap berbagai isu dan strategi optimalisasi pengelolaan BUMDes berdasarkan potensi desa setempat. Aktivitas ekonomi utama yang dilaksanakan saat ini telah terintegrasi dengan berrbagai program pembangunan desa, misalnya penyaluran bantuan dana $\mathrm{PKH}$, pengelolaan layanan air bersih, pembayaran tagihan listrik. Namun demikian, Pengurus menyadari perlu melakukan re-orientasi bisnis BUMDes agar dapat memperluas cakupan layanan dan memberi dampak lebih besar bagi kesejahteraan masyarakat Desa Cipanjalu.
\end{abstract}

Keywords: BUMDES; Evaluasi Kinerja; Pengembangan Kapasitas

\section{VILLAGE OWN ENTREPRISE (BUMDES CIPTA RAHAYU) MANAGEMENT CAPACITY IMPROVEMENT IN CIPANJALU VILLAGE, CILENGKRANG SUB DISTRICT, BANDUNG REGENCY}

\begin{abstract}
This article explains the community service (Pengabdian Kepada Masyarakat, PKM) activity by Unpad lecturer during the 2019/2020 academic year which was held in Cipanjalu Village, Cilengkrang Sub-District, Bandung Regency. The PKM location was chosen based on the assignment of the writer as a field supervisor (Dosen Pembimbing Lapangan, DPL) for the Unpad Entrepreneurship field lecture (KKNM Kewirausahaan) activity that was held for one month (January 9th 2020-February 12th 2020). During this PKM activity, the data collection was conducted in the initial process of student's deployment at Cipanjalu Village through observation, discussion, interview
\end{abstract}


and FGD. The independent performance evaluation of Village Own Entreprise (Cipta Rahayu BUMDes) aimed to increase the management capacity of Cipta Rahayu BUMDes in order to optimize its function as a catalyst for the economy of Cipanjalu residents. The independent performance evaluation was done informally with two core management team members, One BUMDes advisor, and 3 facilitators. From this process, we identified various issues and management optimalization strategies based on the potential of the village. The main economic activities that are conducted have been integrated with various village development programs, for example the distribution of Family Hope Program (Program Keliuarga Harapan, PKH) financial assistance, management of clean water, and also payment for electricity. However, BUMDes management realizes the need to re-orient the BUMDes business in order to widen its scope of service and give more contribution to the wellbeing of Cipanjalu Village.

Keywords: BUMDES; Performance Evaluation; Capacity Building

\section{PENDAHULUAN}

Perubahan tatakelola pemerintahan di Indonesia yang sentralistis menjadi lebih terdesentralisasi telah terjadi sejak dua dekade lalu. Pergeseran tersebut, tidak hanya mengubah pola hubungan antara pemerintah pusat dengan daerah, namun berimplikasi pada mekanisme pelaksanaan pengelolaan pemerintahan (Widianingsih et al., 2018). Dalam konteks tata kelola pemerintahan desa, pengesahan UU No. 6/2014 tentang Desa berdampak pada penguatan desa sebagai unit otonom pemerintahan terendah di Indonesia yang diberikan kewenangan untuk mengatur pengelolaan pemerintahan dan pembangunan desa nya untuk mempercepat upaya peningkatan kesejahteraan masyarakat (Amri, 2019; Senjani, 2019). Upaya tersebut diantaranya diwujudkan dengan memberikan alokasi dana desa berkisar Rp 800 juta-Rp1,4 miliar per desa yang diperoleh dari dana gabungan APBN, APBD provinsi, dan APBD kabupaten/kota (Antara, 2019).

Salah satu upaya strategis dalam mendorong produktivitas ekonomi masyarakat desa secara nyata diperkuat oleh UU No. 23/2014 pasa1 213 ayat 1 terkait pendirian Badan Usaha Milik Desa (BUMDes). Data Kemendes mencatat pada bulan December 2018, 61 \% desa dari 74.954 Desa di Indonesia telah mendirikan BUMDes, setidaknya 45.549 BUMDes telah berdiri (Amri, 2019; Sofyani et al., 2019; Tarlani \& Suhirman, 2019). Walaupun jumlah BUMDes berkembang dengan cepat, hasil evaluasi pemerintah yang dilaksanakan pada Rapat Terbatas Kabinet menunjukkan bahwa 2.188 BUMDes yang tidak beroperasi, 1.670 BUMDes belum optimal berkontribusi menggerakkan ekonomi desa (Thomas, n.d.). Data yang sama terjadi di Provinsi Jawa Barat, saat ini dari 5.312 desa yang ada di Jawa Barat, baru 69,5 persen atau 3.695 desa telah mendirikan BUMDes. Berdasarkan informasi dari Pemprov Jawa Barat, tahun 2020 ditargetkan pendirian BUMDes di seluruh Desa di Jawa Barat yang diintegrasikan dengan Program OVOP (One Village One Product) (Antara, 2019). 
Artikel ini menjelaskan kegiatan Pengabdian Kepada Masyarakat (PKM) dosen Unpad pada Semester Ganjil 2019/2020 yang dilaksanakan di Desa Cipanjalu, Kecamatan Cilengkrang, Kabupaten Bandung. Pemilihan lokasi PKM disesuaikan dengan penugasan penulis sebagai Dosen Pembimbing Lapangan (DPL) untuk kegiatan Kuliah Kerja Nyata Mahasiswa (KKNM Kewirausahaan) Unpad yang dilaksanakan selama satu bulan (9 Januari 2020-12 Februari 2020). Untuk kegiatan PKM sendiri, pengumpulan data dilakukan sejak penempatan mahasiswa KKN Kewirausahaan Unpad di Desa Cipanjalu, namun kegiatan evaluasi kinerja BUMDes Cipta Rahayu baru dapat dilakukan setelah KKNM Kewirausahaan selesai karena hambatan teknis. Pelaksanaan evaluasi kinerja dilaksanakan secara informal yang melibatkan pengurus dan Pembina BUMDes Cipta Rahayu. Kegiatan tersebut diawali dengan kunjungan ke Daerah Tujuan Wisata unggulan Desa Cipanjalu di wilayah perkebunan Kina yang dikelola oleh PTPN VIII Bukit Tunggul. Dalam melaksanakan kegiatan evaluasi tersebut, Penulis dibantu oleh dua orang asisten yang menjadi co-author dalam artikel ini.

Berdasarkan hasil observasi, diskusi dan analisis data sekunder, Desa Cipanjalu yang terletak di wilayah perbatasan dengan Kota Bandung dan Kabupaten Bandung Barat memiliki potensi ekonomi yang memadai. Karakteristik wilayah yang didominasi oleh wilayah pertanian dan perkebunan ditunjukkan dengan aktivitas ekonomi masyarakat yang pada umumnya bekerja di sector pertanian dan perkebunan. Sejak awal pendirian Desa di tahun 1987, Desa Cipanjalu menunjukkan perkembangan ekonomi cukup baik. Bahkan kelompok tani kopi di Desa ini telah mampu mengekspor hasil panennya ke Manca Negara. Berdasarkan informasi dari aparat desa, kegiatan ekonomi masyarakat ditopang oleh avitas pertanian, perkebunan, pariwisata dan berbagai macam produk makanan asli desa (home industry) (Widianingsih, 2020).

Namun demikian, berdasarkan hasil opbservasi Tim KKN dan wawancara yang dilakukan Tim PKM, aktivitas ekonomi produktif masyarakat Desa belum terintegrasi dengan kegiatan usaha BUMDes. Operasional BUMDes masih terbatas pada kegiatan-kegiatan layanan masyarakat, misalnya: pengelolaan air bersih, penyediaan layanan pembayaran tagihan listrik dan penyaluran bantuan program Keluarga Harapan (PKH) melalui E-warung. Berbagai usaha ekonomi produktif masyarakat belum dapat difasilitasi dan diintegrasikan dengan aktivitas BUMDes. Hal ini terjadi karena belum terbangunnya kepercayaan dari pelaku usaha 
di Desa untuk mendukung kegiatan ekonomi produktif oleh BUMDes. Di sisi lain BUMDes sendiri belum memiliki perencanaan pengembangan usaha yang komprehensif.

Berdasarkan hasil observasi dan wawancara yang dilakukan dengan pihak terkait, Tim PKM memfokuskan kegiatan PKM pada penguatan kapasitas BUMDes Cipta Rahayu. Kegiatan ini merupakan tahapan awal dari upaya penguatan kapasitas BUMDes yang difokuskan pada proses pemetaan isu strategis pengelolaan BUMDes dan mengaitkannya dengan kondisi aktual Desa. Proses PKM dilakukan secara informal, melalui FGD terbatas antara tim PKM Unpad dengan pengurus lama dan pengurus baru BUMDes Cipta Rahayu. Tujuan Kegiatan ini secara spesifik diarahkan pada upaya untuk melakukan evaluasi kinerja BUMDes Cipta Rahayu secara mandiri dan mendiskusikan arah pengembangan BUMDes.

\section{METODE}

Sebagaimana dikemukakan sebelumnya, pelaksanaan PKM ini merupakan bagian dari kegiatan Kuliah Kerja Nyata Mahasiswa (KKNM Kewirausahaan) Unpad 2020. Penulis menggunakan pendekatan partisipatif yang menerapkan prinsip transformative research secara parsial dengan menggunakan beberapa metode riset dalam pelaksanaan kegiatan (Widianingsih \& Mertens, 2019). Mengingat penulis menjadi Dosen pembimbing lapangan, pengumpulan data dan informasi dibantu oleh 16 orang mahasiswa yang tinggal di Desa Cipanjalu selama satu bulan. Disamping itu data dan informasi lapangan diperoleh dari kegiatan KKNM Tematik Citarum Harum yang dilaksanakan Unpad pada bulan November 2019. Sisi positif pelaksanaan KKN yang dilakukan di Desa yang sama dengan dosen Pembimbing yang tetap memberikan ruang untuk pengembangan program secara terintegrasi dan berkelanjutan. Dalam hal ini, kebijakan pelaksanaan KKN Unpad 2019 dan 2010 dapat dijadikan Best Practice.

Penulis sendiri melakukan serangkaian wawancara dan observasi langsung di Desa Cipanjalu selama kurang lebih 5 bulan, yaitu sejak bulan Oktober 2019 sampai bulan Februari 2020. Data primer dan sekunder dari berbagai sumber digunakan untuk melengkapi analisis masalah dan perencanaan kegiatan PKM ini. Dengan demikian, metode pelaksanaan PKM terdiri dari analisis data sekunder, observasi, wawancara, kunjungan lapangan, diskusi dan Focus Group Discussion. 


\section{Gambar 2. Pelaksanaan Kegiatan PKM Penguatan Kapasitas Pengelolaan BUMDes Cipta Rahayu}

\section{Pelaksanaan Kegiatan}

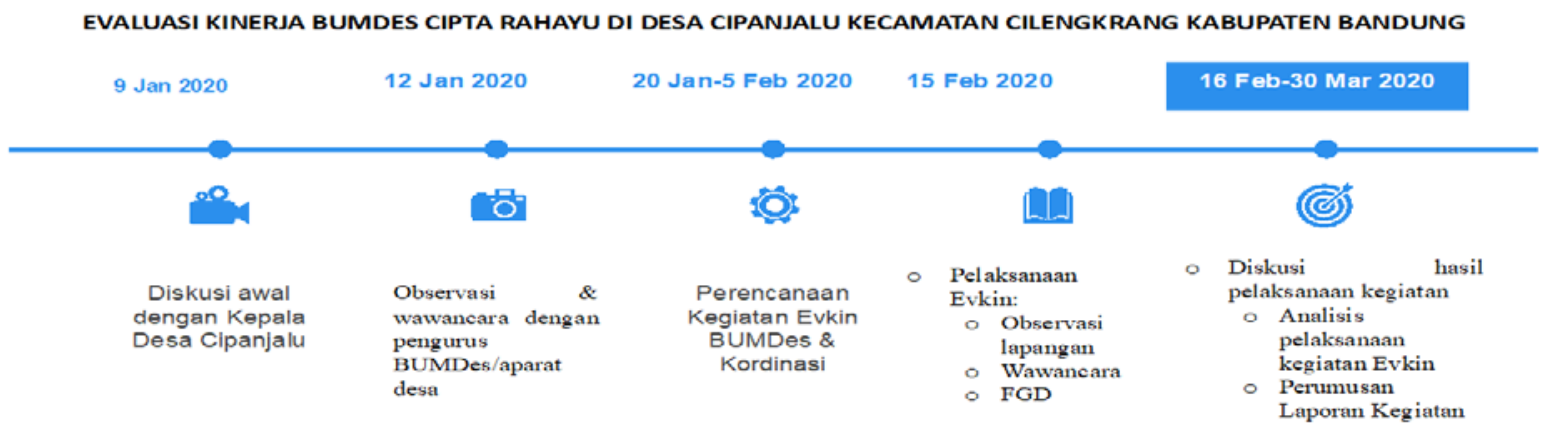

Sumber: Tim Penulis 2020

\section{HASIL DAN PEMBAHASAN}

Desa Cipanjalu secara resmi berdiri sejak tahun 1987 sebagai bagian dari Desa Jatimekar. Seiring dengan perkembangan dinamika pembangunan daerah, pada tahun 1990, Desa Cipanjalu dimekarkan dan menjadi Desa mandiri sebagai bagian dari Kecamatan Cilengkrang, Kabupaten Bandung. Sedangkan Desa Jatimekar berubah status menjadi Kelurahan Pasir Jati Kecamatan Ujungberung Kota Bandung (Desa Cipanjalu, 2016). Posisi geografis Desa Cipanjalu berada di wilayah perbatasan dengan Kota Bandung dan Kabupaten Bandung Barat. Secara administratif Desa Cipanjalu terdiri dari 11 RW yang terletak di kaki Gunung Palasari dan Gunung Manglayang. Walaupun jarak tempuh ke Desa Cipanjalu berkisar antara 10-15 menit dari alun-alun Ujung berung, topografi wilayah Desa Cipanjalu terletak di dataran tinggi yang didominasi lahan perkebunan dan perhutanan. Kawasan hutan lindung berada dalam kewenangan Dinas Perhutanan, sedangkan perkebunan kina Bukit Tunggul merupakan wilayah yang dikelola oleh PTPN VIII. Berdasarkan wawancara dengan apparat desa Cipanjalu, jumlah Penduduk Desa Cipanjalu terdiri dari 5600 orang, mayoritas penduduk Desa Cipanjalu bekerja sebagai petani, pekebun, peternak, buruh lepas, dan pedagang. Dibandingkan dengan desa lain di Kecamatan Cilengkrang, rata-rata pendidikan akhir masyarakat Desa Cipanjalu lulusan SMP/SMA (Dwiki Ramadan Rahman, 2019; Widianingsih, 2020). Mengacu pada data dari Kemendes dan DT, Index Pembangunan Desa Cipanjalu masuk dalam kategori Desa berkembang (Kemendes, 2020). 


\section{Gambar 3. Peta Desa Cipanjalu Kecamatan Cilengkrang Kabupaten Bandung}

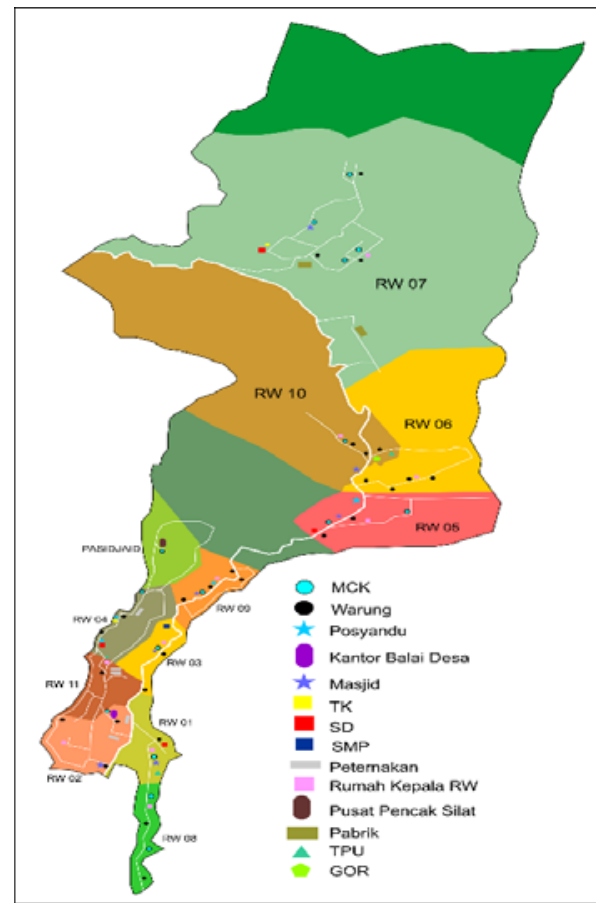

Sumber: (Dwiki Ramadan Rahman, 2019)

Secara umum Desa Cipanjalu mudah diakses dari desa lain dan memiliki potensi pengembangan ekonomi berbasis pertanian dan perkebunan yang memadai. Sejak awal pemekaran Desa, Cipanjalu aktif terlibat dalam berbagai program pembangunan. Sebagai wilayah yang didominasi oleh sektor pertanian, Desa Cipanjalu, khususnya di Kampung Pasirluhur pernah menjadi percontohan program KRPL (Kawasan Rumah Pangan Lestari). Potensi ekonomi lain dihasilkan dari tanaman kopi di kampung Palintang yang tercatat sebagai salah satu program unggulan Badan Ketahanan Pangan dan Pelaksana Penyuluhan (BKPPP). Dari sector pariwisata alam nama tahun 2013 menjadi Wisata Kebun Kina Bukit Unggul). Lokasi wisata ini dikelola oleh PT. Perkebunan Nusantara (PT PN) VIII dan pernah tercatat sebagai lokasi wisata alam dengan kunjungan tertinggi di bandingkan daerah tujuan wisata (DTW) 14,28\% lainnya di Kabupaten Bandung (Wanti et al., 2014). Pengembangan Kawasan wisata ini memberikan dampak positif bagi masyarakat sekitar, utamanya yang memiliki kios-kios makanan di lokasi wisata yang mendapat dukungan permodalan dari program PNPM Mandiri Perdesaan.

Mengacu pada hasil penelitian Wanti, dkk, menunjukkan bahwa Wisata Perkebunan Kina Bukit Unggul memiliki total economic value, pada tahun 2009 tercatat surplus konsumen sebesar Rp 1.108.054.900.- (Wanti et al., 2014). Pengurus BUMDes Cipta Rahayu optimis 
bahwa DTW Bukit Unggul dapat dijadikan pendorong optimalisasi Peran BUMDes dalam meningkatkan kesejahteraan masyarakat Desa Cipanjalu. Hal ini berbeda dengan pandangan Kepala Desa yang kurang mendukung pengembangan daerah tujuan wisata karena dianggap memiliki kontribusi rendah terhadap pembangunan Desa. Bahkan, Daerah Wisata tersebut dianggap memberikan dampak negatif, misalnya terjadinya kemacetan. Menurut hemat penulis, belum adanya kerjasama formal dalam pengelolaan DTW Bukit Unggul antara Pemerintah Desa Cipanjalu, BUMDes Cipta Rahayu dan PTPN VIII menyebabkan dampak ekonomi pengembangan DTW tersebut terbatas pada penduduk yang tinggal di Kawasan perkebunan saja dan kurang memberikan dampak terhadap masyarakat Desa Cipanjalu.

Keberhasilan pengelolaan Daerah Wisata Bukit Unggu tidak berlanjut, sejak tahun 2013, muklai terjadi penurunan pengunjung karena adanya perubahan tata kelola di PTP VIII (Wanti et al., 2014). Ketika PKM ini dilaksanakan, ditemukan bahwa Wisata Kebun Kina Bukit Unggul sudah tidak terkelola dengan baik. Survey lapangan yang dilakukan Bersama dengan Pengurus dan Pembina BUMDes Cipta Rahayu menunjukkan DTW Bukit Unggul yang tidak terawat dan sama sekali tidak ada pengunjung. Berbagai fasilitas pariwisata, seperti penjualan tiket, sepeda gantung, toilet, bangku-bangku taman, tenpat karaoke, danau kecil, dan tower flying fox semuanya dalam keadaan rusak. Para pedagang pun sudah tidak melakukan aktivitas nya lagi, kios-kios rusak parah. Hal ini menjadi perhatian Pengurus BUMDes karena DTW ini pada awalnya dianggap sebagai salah satu potensi ekonomi yang dapat dikerjasamakan dengan BUMDes Cipta Rahayu.

\section{Gambar 4. Kondisi Daerah Tujuan Wisata Bukit Unggul yang tidak terurus}

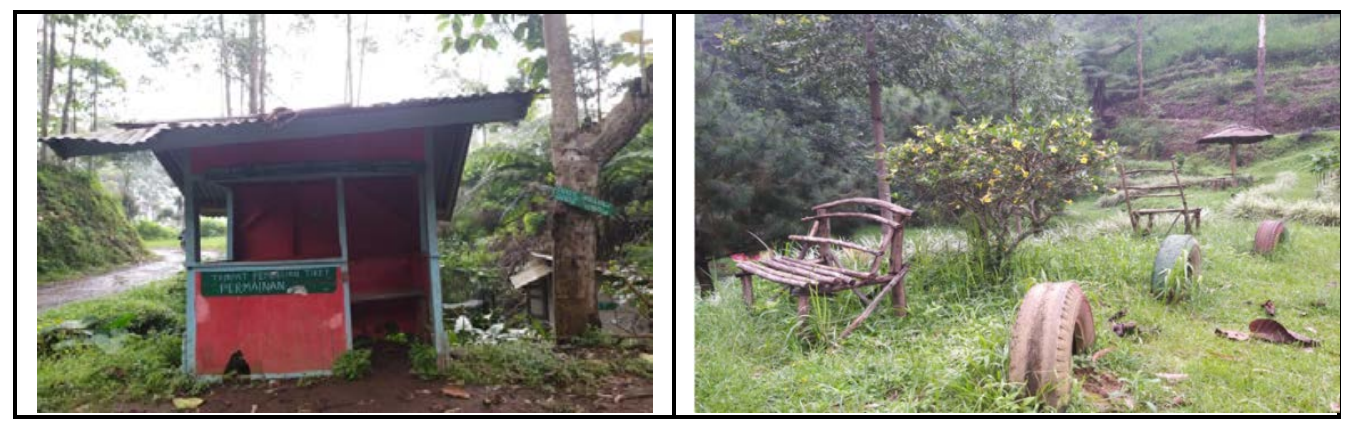




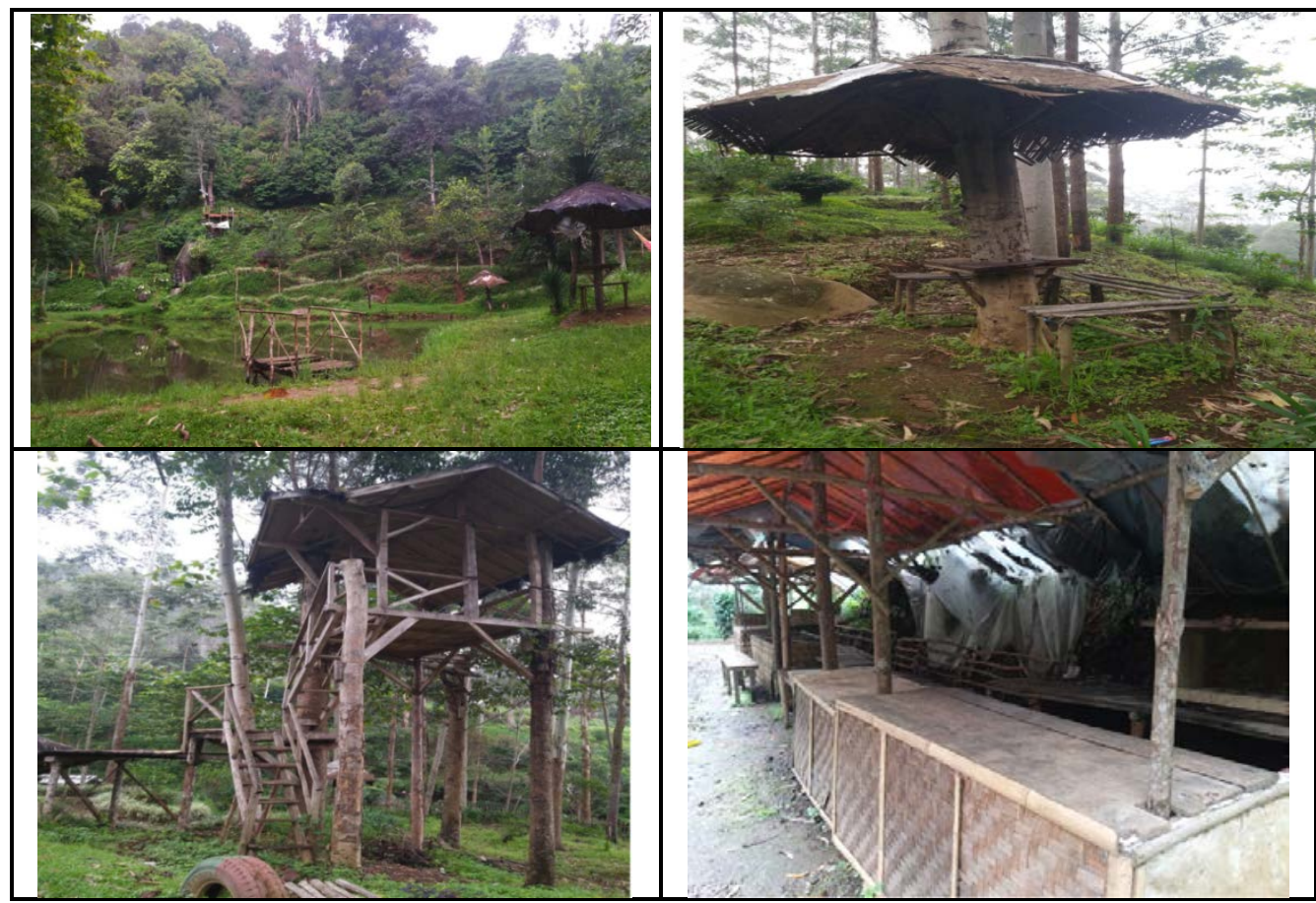

Sumber: Data Lapangan Februari 2020

BUMDes Cipta Rahayu yang didirikan tahun 2016 telah memiliki berbagai kegiatan ekonomi produktif sesuai dengan tujuan pendirian BUMDes yang diatur dalam Pasal 2 Permendesa No, 4/2015. Pada hakikatnya, pendirian BUMDes memiliki tujuan:

“Meningkatkan perekonomian Desa; mengoptimalkan aset desa agar bermanfaat untuk kesejahteraan desa; Meningkatkan usaha masyarakat dalam pengelolaan potensi ekonomi desa; mengembangkan rencana kerja sama usaha antar desa dan/atau dengan pihak ketiga; menciptakan peluang dan jaringan pasar yang mendukung kebutuhan layanan umum warga; membuka lapangan kerja; meningkatkan kesejahteraan masyarakat melalui perbaikan pelayanan umum, pertumbuhan dan pemerataan ekonomi desa; dan meningkatkan pendapatan masyarakat desa dan Pendapatan Asli Desa”.

Kegiatan BUMDes Cipta Rahayu meliputi kegiatan ekonomi dan pelayanan masyarakat yang terdiri dari: pengelolaan air bersih, penyediaan layanan pembayaran tagihan listrik dan penyaluran bantuan program Keluarga Harapan (PKH) melalui E-warung. Aktivitas ini telah sesuai dengan fungsi utama BUMDes sebagai Lembaga ekonomi desa yang menjalankan fungsi komersil dan pelayanan. Dalam konteks pelayanan pembayaran tagihan listrik misalnya, BUMDes Cipta Rahayu telah bekerja sama dengan Bank Mandiri. Namun demikian, kegiatan ekonomi BUMDes Cipta Rahayu belum terintegrasi dengan aktivitas 
ekonomi masyarakat. Hal ini terkonfirmasi dari data lapangan di RW 03 lokasi KKNM Kewirausahaan Unpad TA 2019/2020.

Pengelolaan Air Bersih sebagai bentuk pelayanan masyarakat telah dilaksanakan oleh BUMDes Cipta Rahayu di seluruh wilayah Desa Cipanjalu yang terdiri dari 11 Rukun warga. Dengan posisi geografis di bawah kaki gunung Manglayang. Sumber mata air yang ada di Desa Cipanjalu berasal dari Gunung Palasari, Gunung Parangpang dan Gunung Tanjungsari . Desa Cipanjalu memiliki 35 Mata Air produktif yang digunakan untuk masyarakat Desa serta pengusaha local. Layanan air bersih menggunakan gravitasi bumi memanfaatkan tofografi wilayah. Saat ini penyaluran air telah menggunakan Teknik perpipaan, pipa utama dari Mata Air dibangun dan dikelola oleh BUMDes. Penyaluran air ke masyarakat/rumah tangga diambnil dari pipa utama dan menggunakan meteran air. Kerusakan dan kebocoran pipa utama menjadi tanggungjawab BUMDes, sedangkan pipa kecil perawatannya menjadi tanggungjawab pelanggan. Saat ini pelanggan air bersih di Desa Cipanjalu terdiri dari 2751 Kepala Keluarga yang tersebar di 11 RW, data pelanggan air bersih adalah sebagai berikut:

Tabel 1. Data Pelanggan Air Bersih yang dikelola BUMDes Cipta Rahayu

\begin{tabular}{|c|c|r|r|}
\hline RW & Sumber Mata Air & $\begin{array}{c}\text { Jumlah Pelanggan } \\
(\mathrm{KK})\end{array}$ & Prosentase \\
\hline 01 & Sirah Sirebu & 335 & 12,18 \\
\hline 02 & Sirah Sirebu & 105 & 3,82 \\
\hline 03 & Sirah Sirebu & 96 & 3,49 \\
\hline 04 & Sirah Sirebu & 189 & 6,87 \\
\hline 05 & Gunung Putri & 205 & 7,45 \\
\hline 06 & Gunung Putri & 190 & 6,91 \\
\hline 07 & Bukit Tunggul & 550 & 19,99 \\
\hline 08 & Sirah Sirebu & 289 & 10,51 \\
\hline 09 & Palintang & 450 & 16,36 \\
\hline 10 & Gunung Putri & 172 & 6,25 \\
\hline 11 & Sirah Sirebu & 170 & 6,18 \\
\hline TOTAL & & 2751 & \\
\hline
\end{tabular}

Sumber: Data Lapangan Februari 2020

Walaupun terdapat 35 Mata Air aktif di Desa Cipanjalu, saat ini layanan air bersih diperoleh dari 4 Mata Air. Pengembangan Jaringan perpipaan yang bersumber dari Gunung Putri menggunakan dana PANSIMAS yang melayani 3 RW (05, 06 dan 10) mencakup 565 KK atau 20,54 \% jumlah pelanggan. Berdasarkan hsil observsi dan wawancara dengan masyarakat desa Cipanjalu, banyaknya sumber air belum dapat menyelesaikan isu kekurangan air di Desa Cipanjalu, utamanya selama musim kemarau kebutuhan untuk sector usaha 
produktif, seperti pertanian, peternakan, dan kebutuhan lainnya terhambat. Beberapa warga kesulitan untuk mendapatkan air bersih. Alternatif sumber air diperoleh dari sumur bor, namun air yang didapatkan keruh (berwarna kekuningan).

Problematika tatakelola air bersih di Desa Cipanjalu masih dianggap sensitif, baik oleh masyarakat setempat, maupun aparat desa karena sejak lama beberapa mata air yang berlokasi di Desa Cipanjalu telah digunakan untuk kepentingan bisnis oleh beberapa pengusaha lokal di Desa Pasirwangi yang berbatasan dengan Desa Cipanjalu. Kondisi ini sangat ironis, 35 Mata Air ada di Desa Cipanjalu belu dapat dimanfaatkan secara optimal oleh masyarakat. Setiap musim kemarau, masalah kekurangan air sering terjadi. Pada saat KKNM Kewirausahaan Unpad 2019/2020 maupun KKNM Tematik Citarum Harum Unpad tahun 2019 dilaksanakan, mahasiswa terpaksa tinggal di Desa Pasirwangi karena sulitnya memperoleh akses air bersih. Padahal, setiap hari puluhan mobil tangki air keluar masuk Desa Pasirwangi untuk dipasarkan ke wilayah Metropolitan Bandung Raya bahkan ke Kabupaten Purwakarta.

Peran BUMDes Cipta Rahayu dalam menyediakan layanan penyediaan air bersih dilaksanakan untuk menyalurkan air kepada masyarakat yang terdaftar sebagai pelanggan air dan melakukan pengontrolan terjadwal baik di Hulu (Sumber air) maupun pada pipa air utama. Dengan cakupan layanan PDAM yang terbatas, Pengelolaan air bersih oleh BUMDes menjadi trend positif di Indonesia. Namun demikian, riset menunjukkan baru ada 2 Bumdes di Jawa Barat dan Bali yang berhasil mengembangkan pengelolaan air menjadi air kemasan, misalnya di Desa Dawan Kaler, Dawan, Kulungkung Bali dengan merek UDAKA. Di Garut, inovasi air minum jenis Hexagonal diproduksi BUMDes di Desa Sukarame (Senjani, 2019).

Menurut Manan dan Wahyunandi, setidaknya terdapat lima klasifikasi usaha BUMDes, yaitu usaha usaha penyewaan, bisnis social, usaha perantara, berdagang, bisnis keuanagn dan usaha Bersama (Manan \& Wahyunadi, 2019). Saat ini, BUMDes Cipta Rahayu menjalankan bisnis social dalam bentuk pelayanan air minum dan penyaluran bantuan Program Keluarhga Harapan, serta usaha perantara (brokering) menerima pembayaran tagihan listrik yang dikerjasmakan dengan Bank Mandiri. Usaha-usaha tersebut belum mampu menempatkan BUMDes sebagai pengerak roda perekonomian masyarakat. Lambannya pengembangan usaha BUMDes Cipta Rahayu boleh jadi disebabkan oleh fasilitas kerja yang sangat minim sebagaimana terlihat pada Gambar 5. Saat ini layanan BUMDes dilakukan di kantor Desa Cipanjalu karena ruang serbaguna tidak memiliki alat kerja yang memadai. Pada Gambar 5 
nampak papan nama yang rusak dan terkelupas, ruangan kerja BUMDes juga tidak memiliki perlengkapan kantor yang memadai.

\section{Gambar 5. Kondisi Papan Nama dan Kantor BUMDes Cipta Rahayu}

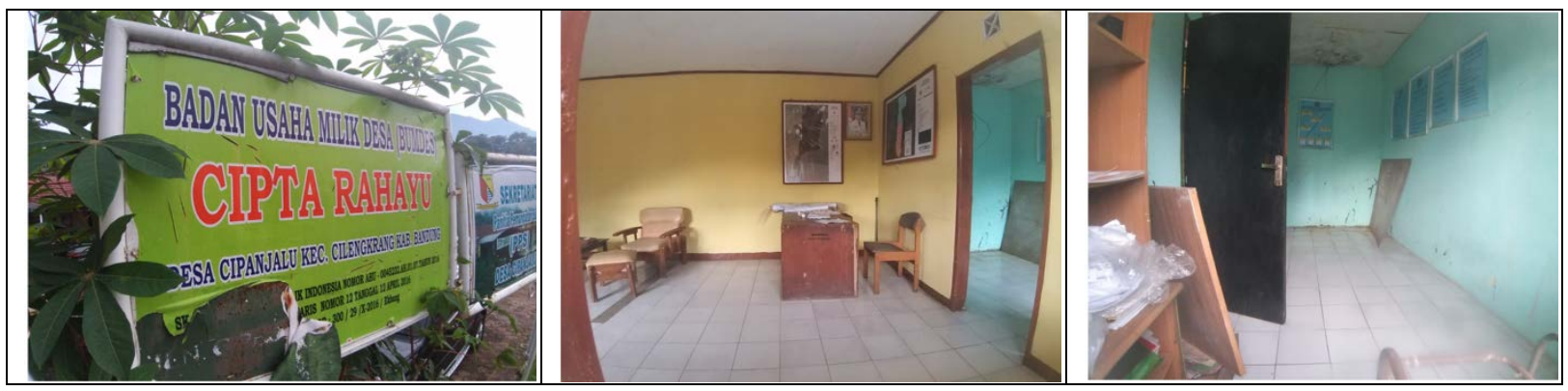

Sumber: Data Lapangan Januari 2020

Gambar 6. Pelaksanaan PKM Penguatan Kapasitas Pengelolaan BUMDes Cipta Rahayu dan Peta Konteks Isu Hasil Diskusi Evaluasi Kinerja BUMDes Desa Cipanjalu

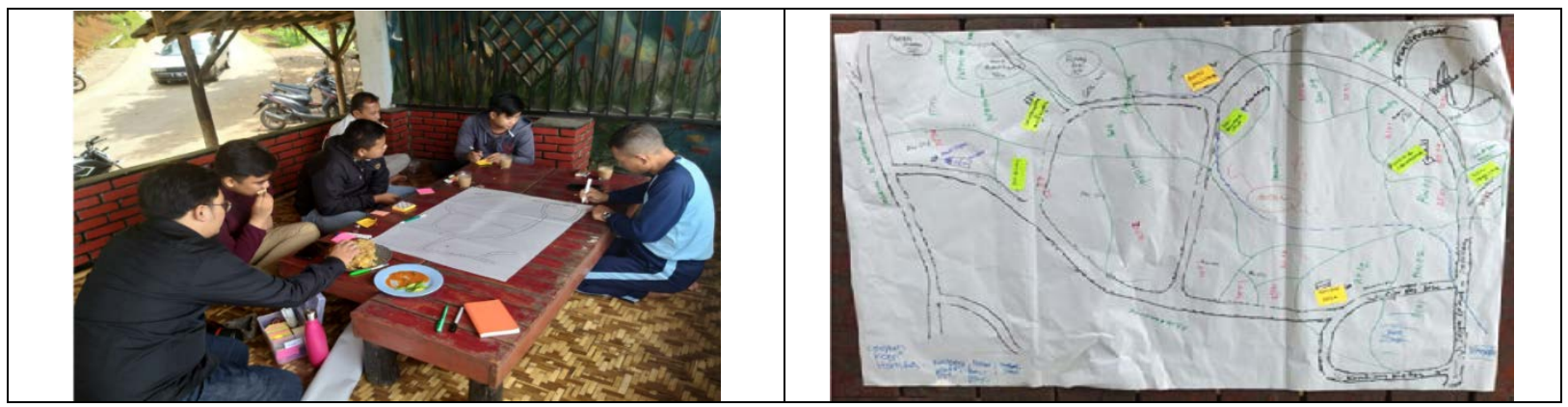

Sumber: Data Lapangan Februari 2020

Kegiatan PKM ini dilaksanakan secara informal dengan pengurus BUMDes lama dan baru, diskusi difokuskan pada identifikasi isu strategis dan jenis-jenis layanan BUMDes yang telah dilakukan selama ini, serta potensi apa yang dapat dikembangkan untuk memperkuat kinerja BUMDes ke depan. Tahapan selanjutnya dari kegiatan PKM ini adalah melakkan pertemuan formal dengan Pengurus Inti BUMDes Cipta Rahayu dan Stakeholder terkait untuk menemukan strategi terbaik dalam mengintegrasikan aktivitas BUMDes dengan kegiatan ekonomi produktif masyarakat.

\section{SIMPULAN}

UU tentang Otonomi Desa memberikan peluang lebih besar bagi Pemerintah Desa untuk mengelola Pembangunan Desa secara mandiri. Kemandirian tersebut diperkuat dengan adanya aturan yang mendorong kegiatan ekonomi produktif di Desa melalui BUMDes. Namun demikian, performa BUMDes tidak merata, belum semua BUMDes mampu melaksanakan fungsi ekonomi dan pelayanan public secara optimal. 
Pada konteks BUMDes Cipta Rahayu, belum terintegrasinya kegiatan ekonomi produktif dengan aktivitas BUMDes disebabkan beberapa faktor, seperti belum ada nya peta jalan dan perencanaan program BUMDes yang komprehensif, belum terbangunnya komunikasi intensif antara pelaku usaha di Desa dengan pengurus BUMDes, dan belum adanya fasilitas kerja yang memadai, belum optimalnya dukungan dan sinerji dari Lembaga-lembaga di Desa untuk memperkuat kegiatan BUMDes. Salah satu factor yang berkontribusi pada lambannya pengembangan BUMDes Cipta Rahayu adalah masih adanya perbedaan persepsi dan pemahaman pengurus dan masyarakat pelaku usaha dalam pengembangan BUMDes.

Kepemimpinan dan komitmen dari Kepala desa dan ketua BUMDes dapat menjadi pendorong akselerasi pengembangan BUMDes. Dalam konteks pengembangan kapasitas pengelolaan BUMDes Cipta Rahayu diperlukan pendekatan khusus utamanya membuka komunikasi intensif antara BUMDes degan pelaku ekonomi di desa Cipanjalu yang didasarkan pada trust dan transparansi.

\section{UCAPAN TERIMAKASIH}

Penulis mengucapkan terima kasih kepada Rektor Universitas Padjadjaran atas penugasan pelaksanaan KKN kewirausahaan dan PKM ini. Penulis mengucapkan terima ksih lepada Kepala Desa dan Aparat Desa Cipanjalu yang telah berkenan mengizinkan mahasiswa kami melaksanakan KKNM Kewirausahaan di Desa Cipanjalu selam satu bulan penuh. Disamping itu ucapan terima kasih disampaikan kepada Pengurus dan Pembina BUMDES Cipta Rahayu, Desa Cipanjalu yang telah memberikan infomasi serta waktu untuk melaksanakan kegiatan PKM ini. Ucapan terima kasih disampaikan kepada para mahasiswa peserta KKN Kewirausahaan di Desa Cipanjalu yang telah melaksanakan survey dan melakukan berbagai kegiatan terkait KKN Kewirausahaan di Desa Cipanjalu.

\section{DAFTAR PUSTAKA}

Amri, K. (2019). Bumdes Acceleration Towards Mandiri Village. Iapa Proceedings Conference, 268. https://doi.org/10.30589/proceedings.2019.236

Antara. (2019). Jabar targetkan bentuk 746 BUMDes pada tahun 2020. https://jabar.antaranews.com/berita/124488/jabar-targetkan-bentuk-746-bumdespada-tahun-2020 
Desa Cipanjalu. (2016). Sejarah Desa. https://www.cipanjalu.desa.id/first/artikel/99

Dwiki Ramadan Rahman, dkk. (2019). Laporan KKN Citarum Harum Unppad di Desa Cipanjalu Kecamatan CIlengkrang KAbupaten Bandung.

Hanida, R. P., Irawan, B., Syamsurizaldi, S., \& Rahayu, W. K. (2017). Collaboration of Stakeholders In Formation and Development Nagari-Owned Enterprise. Policy \& Governance Review. https://doi.org/10.30589/pgr.v1i3.58

Manan, A., \& Wahyunadi. (2019). BUMDes Penggerak Ekonomi Desa. BALILATPO, KemendesPDTT.

https://lumbungfile.kemendesa.go.id/index.php/s/desa_contoh?path=\%2Febook\%2F Bumdes\%2F2019\#pdfviewer

Muzanah Zain, H. (2018). EFEKTIVITAS BADAN USAHA MILIK DESA DALAM MENINGKATKAN PENDAPATAN ASLI DESA (Studi kasus : Badan Usaha Milik Desa “Amarta.” Program Studi Ilmu Pemerintahan Universitas Muhammadiyah Yogyakarta.

Senjani, Y. P. (2019). PERAN SISTEM MANAJEMEN PADA BUMDES DALAM PENINGKATAN PENDAPATAN ASLI DESA. Kumawula: Jurnal Pengabdian Kepada Masyarakat, 2(1), 23. https://doi.org/10.24198/kumawula.v2i1.23698

Sofyani, H., Atmaja, R., \& Rezki, S. B. (2019). Success Factors of Village-Owned Enterprises (BUMDes) Performance in Indonesia: An Exploratory Study. Journal of Accounting and Investment, 20(2). https://doi.org/10.18196/jai.2002116

Tarlani, M., \& Suhirman, M. (2019). Behind the Joint BUMDes (Badan Usaha Milik Desa Bersama) (Insight the motive for establishing joint BUMDes Danar Garut). Proceedings of the International Conference on Rural Studies in Asia (ICoRSIA 2018). https://doi.org/10.2991/icorsia-18.2019.52

Thomas, V. F. (n.d.). Kenapa Ribuan BUMDes Mangkrak Meski Dana Desa Triliunan Rupiah? Retrieved April 6, 2020, from https://tirto.id/kenapa-ribuan-bumdesmangkrak-meski-dana-desa-triliunan-rupiah-enpb

Wanti, L. W., Syaukat, Y., \& Juanda, B. (2014). Analisis Nilai Ekonomi Wisata Kebun Kina Bukit Unggul Kabupaten Bandung. Journal of Agriculture, Resource and Environmental Economics, 1(2), 44-55. https://doi.org/10.29244/jaree.v1i2.11801 
Widianingsih, I. (2020a). STRATEGI PENINGKATAN PENYADARAN ISU LINGKUNGAN BAGI SISWA SEKOLAH DASAR MELALUI PERMAINAN ULAR TANGGA: KONTRIBUSI UNPAD UNTUK PROGRAM CITARUM HARUM. Kumawula: Jurnal Pengabdian Kepada Masyarakat. https://doi.org/10.24198/kumawula.v3i1.24598

Widianingsih, I. (2020b). STRATEGI PENINGKATAN PENYADARAN ISU LINGKUNGAN BAGI SISWA SEKOLAH DASAR MELALUI PERMAINAN ULAR TANGGA: KONTRIBUSI UNPAD UNTUK PROGRAM CITARUM HARUM. Kumawula: Jurnal Pengabdian Kepada Masyarakat, 3(1), 106. https://doi.org/10.24198/kumawula.v3i1.24598

Widianingsih, I., McLaren, H. J., \& McIntyre-Mills, J. (2018). Decentralization, Participatory Planning, and the Anthropocene in Indonesia, with a Case Example of the Berugak Dese, Lombok, Indonesia. In Janet McIntyre-MillsNorma RommYvonne CorcoranNantes (Ed.), Balancing Individualism and Collectivism Social and Environmental Justice (1st ed., pp. 271-284). Springer. https://doi.org/10.1007/978-3-319-580142_15

Widianingsih, I., \& Mertens, D. M. (2019). Transformative research and the sustainable development goals : challenges and a vision from Bandung, West Java. 6(x), 27-35.

Widianingsih, I., \& Morrell, E. (2007). Policy Studies PARTICIPATORY PLANNING IN INDONESIA PARTICIPATORY PLANNING IN INDONESIA Seeking a new path to democracy. Policy Studies. https://doi.org/10.1080/01442870601121320 